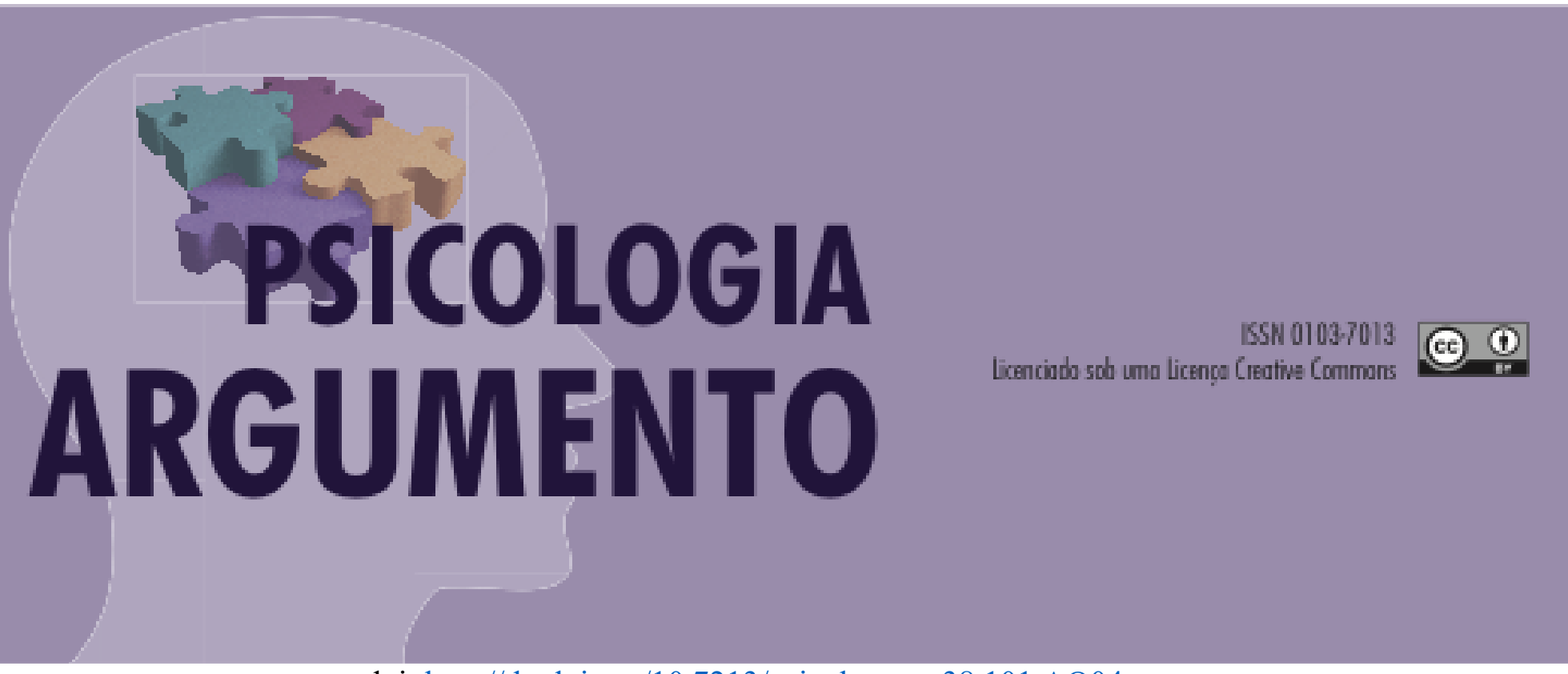

doi: $\underline{\text { http://dx.doi.org/10.7213/psicolargum.38.101.AO04 }}$

\title{
Suporte social e enfrentamento de pacientes com Doença de Parkinson e seus cuidadores familiares
}

\author{
Social support and coping strategies of Parkinson's disease patients and their family \\ caregivers
}

Apoyo social y afrontamiento de pacientes con enfermedad de Parkinson y sus

cuidadores familiares

Thamires Medeiros de Santana

Psicóloga formada pelo Centro Universitário de Brasília, thamy-medeiros15@hotmail.com

Orcid: https://orcid.org/0000-0001-6484-6628

Marina Kohlsdorf

Doutora em Psicologia pela Universidade de Brasília, professora do Centro Universitário de

Brasília, marina.kohlsdorf@ceub.edu.br Orcid: https://orcid.org/0000-0002-7029-3270

Tereza Cristina Cavalcanti Ferreira de Araujo

Doutora em Psicologia pela Université Paris-Nanterre, professora da Universidade de Brasília, araujotc@pq.cnpq.br Orcid: https://orcid.org/0000-0002-5204-8124

\begin{abstract}
A Doença de Parkinson (DP) consiste em uma cronicidade de natureza neurodegenerativa e progressiva. Em razão da escassez de estudos nacionais sobre o tema, realizou-se uma pesquisa com os seguintes objetivos: identificar e analisar a rede de suporte social e as estratégias de enfrentamento de pessoas acometidas por essa enfermidade; analisar o suporte social prestado e o papel do cuidador familiar. Trata-se de uma pesquisa qualitativa, a qual utilizou como recurso a observação participante e entrevistas semiestruturadas. Participaram do estudo cinco portadores
\end{abstract}

Resumo 
da DP e cinco cuidadores familiares. Os dados foram analisados conforme o método hermenêutico-dialético. Os resultados confirmaram a relevância do suporte social no enfrentamento da DP e as principais estratégias de enfrentamento encontradas foram: suporte social familiar e grupos de apoio. Recomenda-se que futuras pesquisas investiguem os efeitos das políticas públicas direcionadas aos portadores da Doença de Parkinson.

Palavras-chave: Doença de Parkinson. Suporte Social. Enfrentamento. Cuidador Familiar.

\section{Abstract}

Parkinson's disease (PD) consists of a neurodegenerative and progressive chronicity. Due to the lack of national studies on this matter, a survey was conducted with the following aims: identifying and analysing the social support network and the coping strategies of people affected by this disease; analysing the provided social support and the role of the familiar caregiver. It is a qualitative research, which used participant observation and semi-structured interviews as a resource. Five patients with $P D$ and five family caregivers participated in the research. The data were analysed according to the hermeneutic-dialectic method. The results confirmed the importance of the social support in coping with PD and the main coping strategies found were family social support and support groups. Future researches are recommended to investigate the effects of public policies directed at people diagnosed with Parkinson's disease.

Keywords: Parkinson's Disease. Social Support. Coping. Family Caregiver.

\section{Resumen}

La enfermedad de Parkinson (EP) consiste en una enfermedad cónica neurodegenerativa y progresiva. Debido a la escasez de estudios nacionales sobre el tema, se realizó una pesquisa con los siguientes objetivos: identificar y analizar la red de apoyo social y las estrategias de afrontamiento para personas afectadas por esa enfermedad; analizar el apoyo social prestado y el papel del cuidador familiar. Esa es una pesquisa cualitativa, la cual utilizó como recurso la observación participante y entrevistas semiestructuradas. Participaron de la pesquisa cinco pacientes con la EP y cinco cuidadores familiares. Los datos fueron analizados según el método hermenéutico-dialécto. Los resultados confirmaron la relevancia del apoyo social en el afrontamiento de la EP y las principales estrategias encontradas fueron: el suporte social familiar y los grupos de apoyo. Se recomienda que las investigaciones futuras investiguen los efectos de las politicas públicas dirigidas a las personas con enfermedad de Parkinson.

Palabras clave: Enfermedad de Parkinson. Apoyo Social. Afrontamiento. Cuidador Familiar.

\section{Introdução}

Em um cenário mundial de mudanças sociodemográficas e epidemiológicas, constata-se um intenso envelhecimento populacional ao qual se associa um notável aumento de doenças crônicas. Cabe ressaltar que, na atualidade, a Doença de Parkinson (DP) tem sido reconhecida como a segunda doença neurodegenerativa mais frequente, cujas adversidades impactam indivíduos com 40 a 50 anos de idade, que se encontram em uma fase socialmente produtiva. Estudos internacionais revelam que, até 2030, o número de pessoas comprometidas pela doença mais que dobrará (Dorsey et al., 2007).

No Brasil, conforme dados publicados na Portaria n²28 do Ministério da Saúde, de 10 de Maio de 2010, a DP atinge pessoas de todas as classes socioeconômicas e grupos 
étnicos. Estima-se que 220 mil pessoas sofram com tal condição, havendo uma prevalência de 3\% na população acima de 65 anos em nosso país (Ferreira, 2016). Também é relevante realçar o Projeto de Lei no 605, de 2015, que estabelece diretrizes para uma política de atenção integral aos portadores da Doença de Parkinson no âmbito do Sistema Único de Saúde - SUS.

\section{Doença de Parkinson: aspectos clínicos gerais}

A doença de Parkinson (DP) é caracterizada como um distúrbio neurodegenerativo de caráter progressivo e incapacitante do sistema nervoso central, proveniente da morte de neurônios produtores de dopamina da substância nigra (negra), o que acarreta a redução das células que fabricam dopamina na via negroestriatal e dos neurônios que contém neuromelanina no tronco cerebral, isso ocorre principalmente na camada ventral da região compacta da substância nigra e do locus ceruleus (lócus cerúleos) (Cabreira \& Massano, 2019; Valcarenghi, 2015).

A alteração do sistema nervoso central, provocada pela DP, é marcada por distúrbios motores e disfunções posturais e cognitivas. Uma vez que os sinais e sintomas são identificados, estima-se que já tenha ocorrido a perda de, mais ou menos, $60 \%$ dos neurônios dopaminérgicos e que $80 \%$ do conteúdo de dopamina no estriado esteja inferior ao normal, o que, por sua vez, resulta na redução da atividade das áreas motoras do córtex cerebral, acarretando desaceleração de movimentos voluntários (Cabreira \& Massano, 2019).

A etiologia da doença de Parkinson é idiopática, ou seja, a doença se manifesta espontaneamente ou a partir de causas ainda não suficientemente conhecidas. Segundo Cabreira e Massano (2019), existem estudos que consideram que a doença de Parkinson seja decorrente de um conjunto de fatores, os quais predispõem o surgimento da doença, tais como: genéticos, toxinas ambientais, anormalidades mitocondriais, estresse oxidativo e alterações do envelhecimento.

No que concerne aos sinais e sintomas da doença de Parkinson, se iniciam de forma quase que imperceptível, progredindo lentamente e, às vezes, sendo associados a outras doenças. A DP é composta por quatro sintomas motores, conhecidos como sinais cardinais: tremor, rigidez, bradicinesia e instabilidade postural (Cabreira \& Massano, 2019; Silva, Dibai Filho, \& Faganello, 2011; Valcarenghi, 2015).

O tremor é referido como um sintoma inicial na DP, sendo o sinal mais frequente e expressivo da doença. Pode ser observado em condições de repouso, diminuindo ou até 
mesmo desaparecendo após o início de alguma ação. É caracterizado como um movimento rítmico, oscilatório, repetitivo e involuntário que envolve, usualmente, as mãos, os braços, os pés e as pernas (Cabreira \& Massano, 2019; Silva, Dibai Filho, \& Faganello, 2011; Valcarenghi, 2015).

A rigidez está presente em quase todos os casos de DP, ocasionando uma limitação na amplitude do movimento articular, tendo como característica uma resistência à movimentação do membro afetado, podendo ocorrer de forma contínua ou intermitente. Pode causar câimbras e afetar a musculatura do tronco, sendo um dos fatores responsáveis pelas alterações posturais (Valcarenghi, 2015; Silva, Dibai Filho, \& Faganello, 2011).

A bradicinesia, sintoma mais incapacitante da DP, corresponde a lentidão dos movimentos, provocando uma pobreza de movimentos e a lentidão para o início e a execução de atos motores, voluntários e automáticos. À medida que a doença progride, a bradicinesia pode atingir o movimento de piscar os olhos e deglutir (Cabreira \& Massano, 2019; Silva, Dibai Filho, \& Faganello, 2011; Valcarenghi, 2015).

A instabilidade postural também está presente nos pacientes com DP, os quais apresentam anormalidades na postura e no equilíbrio, o que se deve à perda de reflexos posturais e resulta em um encurvamento e projeção do corpo para frente, sem o balanço fisiológico dos braços (Cabreira \& Massano, 2019; Silva, Dibai Filho, \& Faganello, 2011; Valcarenghi, 2015).

O diagnóstico da Doença de Parkinson não é simples, posto que várias outras doenças, neurodegenerativas e não neurodegenerativas, podem se desenvolver com o parkinsonismo. O parkinsonismo é uma síndrome que se manifesta por bradicinesia somada a um ou mais sinais cardiais (tremor, rigidez e instabilidade postural), sendo classificado em quatro categorias: primário, secundário, síndromes parkinsonismo-plus e doenças heredodegenerativas. A Doença de Parkinson concerne ao parkinsonismo primário (Pinheiro, 2011).

À vista disso, o diagnóstico se baseia na história clínica detalhada e no exame físico do paciente, identificando-se os sinais e sintomas que compõem o quadro clínico. É importante que exames laboratoriais e tomografia computadorizada do crânio sejam realizados, a fim de que outras doenças sejam afastadas da hipótese diagnóstica. Ademais, instrumentos como a Escala de Hoehn e Yahr (que indica o nível de incapacidade em cinco estágios, de 0 a 5) podem ser utilizados para graduar o nível de incapacidade do paciente (Pinheiro, 2011; Valcarenghi, 2015). 
Com relação aos tratamentos disponibilizados às pessoas com DP, visam essencialmente o controle dos sintomas, uma vez que se trata de uma doença que ainda não tem resolutividade conhecida. Assim, os tratamentos têm como objetivo manter a autonomia e a independência funcional dos indivíduos, de forma preservar a sua qualidade de vida pelo maior tempo possível.

\section{Coping e Suporte Social: breve delimitação conceitual}

A condição de cronicidade, em situação de fragilidade e dependência, pode levar o indivíduo a se deparar com muitos eventos estressores, o que pode comprometer seu bem-estar. As estratégias de coping podem auxiliar as pessoas a gerenciarem eventos estressores e são consideradas habilidades cognitivas, comportamentais e emocionais, adotadas para lidar com demandas específicas, internas ou externas, que provém de situações adversas e são avaliadas como uma sobrecarrega, excedendo os recursos pessoais que o sujeito disponibiliza (Ramos, Enumo, \& Paula, 2015; Straub, 2014).

Isto posto, compreende-se que as estratégias de coping são ações deliberadas, as quais podem ser aprendidas, utilizadas e/ou rejeitadas. De acordo com o modelo proposto por Folkman e Lazarus (1980), as estratégias de coping podem ser divididas em duas categorias funcionais: uma com o foco no problema e outra com o foco na emoção. Quando o foco está no problema, o objetivo é amenizar ou eliminar o evento/estímulo estressor, nesse caso, o estressor é percebido como um problema que deve/pode ser resolvido. Quando o foco está na emoção, o objetivo é aliviar o impacto emocional adverso provocado pelo estressor, assim, há uma mudança de atitude frente ao problema, busca-se melhorar a relação que se tem com este (Ramos, Enumo, \& Paula, 2015; Simonetti \& Ferreira, 2008; Straub, 2014).

De acordo com Cobb (1976), coping e adaptação são processos diferentes. Coping corresponde à manipulação do ambiente a seu favor e adaptação significa mudar a si mesmo na tentativa de se ajustar ao ambiente. No que tange aos doentes de Parkinson, as estratégias de coping podem ser adotadas como uma forma de enfrentamento, uma vez que não podem modificar os efeitos da doença em si. Associadas ao suporte social, essas estratégias podem amenizar os impactos da vivência de cronicidade acarretados pela Doença de Parkinson.

O suporte social pode servir como um motivador para o enfrentamento da DP. De acordo com Sant'Ana e D'Elboux (2019), o suporte social é compreendido, de forma geral, como a existência de pessoas em quem podemos confiar e/ou contar, são pessoas 
que demonstram gostar e se preocupar conosco, que nos valorizam e estão disponíveis para nos ajudar.

O suporte social é também, segundo Cobb (1976), um fator de proteção, sendo capaz de ajudar o indivíduo a enfrentar crises e situações que necessitem de adaptação/mudança. Ainda de acordo com esse autor, o suporte social pode ser dividido em três classes, a primeira delas corresponde a informações que levam o indivíduo a acreditar que é amado e que as pessoas se preocupam com ele (suporte emocional), a segunda, são informações que levam o sujeito a acreditar que é apreciado e valorizado (suporte à autoestima) e a terceira, conduz o indivíduo a crer que pertence a uma rede de comunicação e obrigações mútuas.

O suporte à autoestima encoraja o indivíduo a enfrentar e a tentar dominar o problema. Já o suporte emocional e a sensação de pertencimento, fornecem um clima para que mudanças de identidade ocorram (Cobb, 1976). Pensando na DP, esses suportes são extremamente importantes, uma vez que o indivíduo se vê perdendo autonomia e se tornando cada vez mais um sujeito doente. À medida em que a doença vai se incorporando à identidade do indivíduo, este pode se fragilizar, assim, o suporte social se torna um aliado interessante no acompanhamento dessa mudança.

A família é considerada uma forte fonte de suporte social e exerce especial influência no caso de jovens e idosos (Cobb, 1976; Pinheiro, 1999). Em se tratando dos idosos, a família é considerada como um refúgio, onde eles encontram "proteção, solidariedade e afetividade" (Simonetti \& Ferreira, 2008, p.20). E, em especial para os idosos com DP, a família é o suporte social mais importante (Alvarez et al., 2016).

Além do suporte ofertado pela família, é crucial que as pessoas com DP sejam acompanhadas por diversos profissionais, buscando uma maior compreensão da situação, tendo em vista uma assistência multiprofissional que corresponda às reais necessidades do paciente e de sua família e que contemple as diferentes áreas anatômicas e implicações funcionais afetadas pela doença (Alvarez et al., 2016; Valcarenghi, 2015).

Outra forma de se obter suporte social é através de Grupos de Apoio. O convívio em grupo faz com que as pessoas se sintam úteis e fazendo parte de um coletivo, que lhes apoia e compartilha de sua vivência. Os grupos de apoio possibilitam às pessoas uma sensação de pertencimento e amparo, também facilitam a manutenção da autoestima e autoconfiança dos participantes. Esses grupos buscam estimular os participantes e suas respectivas famílias, através momentos de solidariedade, cooperação e superação 
(Alvarez et al., 2016).

Entende-se que os processos identitários posicionam os indivíduos em suas relações com os demais grupos sociais existentes nos contextos culturais em que estão inseridos. Ao se identificar com um grupo social, um sentimento de pertencimento a este grupo pode ser construído, fazendo com que o sujeito o tenha como uma referência (Madureira \& Branco, 2007). Considerando os portadores de DP e suas famílias, os grupos de apoio podem ser um espaço de construção de identidade e de pertencimento, favorecendo assim, o desenvolvimento de relações e a integração social, colaborando, consequentemente, com a promoção de saúde dos sujeitos envolvidos.

Diante do exposto, empreendeu-se uma pesquisa com os seguintes objetivos: identificar e analisar a rede de suporte social e as estratégias de enfrentamento de pessoas diagnosticadas com a Doença de Parkinson, assim como, analisar o suporte social prestado e o papel do cuidador familiar.

\section{Método}

\section{Participantes}

Trata-se de um estudo de amostra por conveniência. A amostra foi constituída por cinco indivíduos do sexo masculino diagnosticados com DP há pelo menos 10 anos e cinco cuidadores familiares. Do total (10 participantes), três díades participaram (6 participantes), cada díade foi composta por um portador da DP e a sua respectiva esposa/principal cuidadora. Do restante da amostra (4 participantes), um portador da DP não possui cuidador, o outro é casado e reside com a esposa, sua principal cuidadora, a qual não participou do estudo, os outros dois cuidadores possuem cônjuges portadores da DP, os quais não foram entrevistados.

Os portadores da DP tinham idades entre 66 e 83 anos e o tempo de evolução da doença variou de 11 a 29 anos. Os cuidadores familiares tinham idades entre 64 e 77 anos e o tempo como cuidador variou de 4 a 18 anos. Os entrevistados foram identificados pelas iniciais de seus nomes, assim como seus familiares, porém acrescidos da letra "C" de cuidador.

\section{Instrumentos}

Foram utilizados dois roteiros de entrevista semiestruturados para a realização da pesquisa. O primeiro roteiro foi direcionado aos portadores da Doença de Parkinson e 
constitui-se de 11 perguntas, as quais foram elaboradas previamente para investigar: (1) suporte social; (2) formas de enfrentamento; e (3) significado das vivências. O segundo roteiro de entrevista foi direcionado para o principal cuidador familiar dos portadores de DP e constitui-se de nove perguntas, as quais foram elaboradas previamente para investigar: (1) suporte social prestado; (2) papel do cuidador familiar; e (3) qualidade do cuidado ofertado.

\section{Local}

A presente pesquisa se caracteriza como um estudo qualitativo, desenvolvido junto a indivíduos cadastrados na Associação Parkinson Brasília - APB. A APB é uma entidade civil, sem fins lucrativos, criada com o objetivo de congregar e apoiar pessoas portadoras da Doença de Parkinson e seus familiares e/ou cuidadores. Atualmente, conta com 80 parkinsonianos cadastrados, mas somente 40 ativos e participantes, todos residentes em Brasília e entorno. A associação promove diversas atividades com o intuito de: melhorar a qualidade de vida e desenvolver grupos de apoio aos portadores da DP e seus cuidadores familiares; favorecer a integração e a promoção social; divulgar a opinião pública e informar sobre a Doença de Parkinson. São realizadas palestras mensais com diferentes profissionais da área da saúde e atendimentos semanais e gratuitos, com fisioterapeutas, fonoaudiólogos, psicóloga e professor de música.

\section{Procedimentos}

Inicialmente, para garantir o cumprimento das normas éticas na condução de pesquisa com seres humanos, a pesquisa foi submetida ao Comitê de Ética em Pesquisa - CEP, do Centro Universitário de Brasília - UniCEUB, credenciado ao Comitê Nacional de Ética em Pesquisa - CONEP, do Conselho Nacional de Saúde. A pesquisa foi aprovada em 25 de Setembro de 2018, sob o registro 2.917.000/2018. Os demais materiais, como: gravações em áudio das entrevistas, registros transcritos e TCLEs permanecem em arquivo, podendo ser acessados, única e exclusivamente, pela pesquisadora. Os participantes, após o convite para participar da pesquisa, receberam uma explicação prévia sobre o estudo, esclarecendo-se os objetivos e a metodologia da pesquisa. Cada participante recebeu e assinou duas vias do Termo de Consentimento Livre e Esclarecido - TCLE, uma via permaneceu com a pesquisadora e a outra foi entregue ao participante. 
Foi assegurado o sigilo tanto das identidades pessoais dos participantes quanto das informações fornecidas por eles.

Depois da aprovação do Comitê de Ética em Pesquisa, os dados foram coletados por meio de entrevistas semiestruturadas, no período de Setembro a Outubro de 2018, na cidade de Brasília - Distrito Federal, Brasil. As entrevistas foram realizadas individualmente, uma parte na Associação Parkinson Brasília, durante os encontros semanais com os membros da associação e a outra, na residência dos participantes, no dia e horário agendado. Após consentimento, as entrevistas foram gravadas através de um sistema de áudio e tiveram uma duração média de 27 minutos.

\section{Análise dos Dados}

A metodologia empregada nesta pesquisa é entendida como um processo dinâmico que engloba a experiência intuitiva do pesquisador, o fenômeno estudado, o método e a teoria. O pesquisador tem um papel ativo no processo de construção do conhecimento, o qual estabelece uma relação interativa com o entrevistado, desse modo, tem-se a entrevista como um espaço dialógico.

Conforme o método hermenêutico-dialético proposto por Minayo (1992), a análise dos dados foi dividida em três etapas:1. Ordenação dos dados; 2. Classificação dos dados; e 3. Análise final. Uma vez concluídas, as entrevistas foram transcritas na íntegra e submetidas a um processo exaustivo de leitura. Nesta fase inicial também foi feita a organização dos relatos e dos dados coletados durante a observação participante.

A segunda etapa engloba o destaque de trechos significativos e a elaboração das categorias analíticas temáticas, as quais proporcionam uma maior organização e compreensão das informações, visto que abrangem elementos com características comuns que se relacionam entre si, possibilitando a formação de núcleos de significados entre os resultados obtidos (Minayo, 2002).

A terceira etapa envolve a articulação dos dados com o referencial teórico da pesquisa, tendo em vista os objetivos desta. Aqui, busca-se ampliar o conhecimento sobre o assunto pesquisado, articulando-o a realidade social da qual faz parte.

\section{Resultados}


Os resultados que serão apresentados a seguir foram organizados em quatro categorias analíticas temáticas: Aprendendo a viver com a Doença de Parkinson: lidando com o desconhecido, Enfrentando a Doença de Parkinson: superando os obstáculos, Convivendo com a Doença de Parkinson: o olhar de quem cuida e Experiência do cuidador familiar com a Doença de Parkinson: um desafio.

\section{Aprendendo a viver com a Doença de Parkinson: lidando com o desconhecido}

No que concerne ao diagnóstico da doença, alguns participantes relataram ter observado mudanças no funcionamento do próprio organismo e na execução de atividades rotineiras, o que fez com que eles procurassem um médico, G: "Eu senti um tre...tre...tremo... E ai eu fui ao médico e ele fez os testes comigo lá e disse que, que eu tinha Parkinson mesmo" e M: "Diagnóstico foi o seguinte, há 12 anos atrás parecia que eu estava com depressão, eu tratei 2 anos como fosse depressão, fui numa psiquiatra, tomei remédio pra depressão, porque eu sempre fui um cara muito alegre e de repente eu fiquei meio que enfurnado em casa" ainda no que refere a fala de M. é possível destacar outros aspectos, como a dificuldade em se diagnosticar a Doença de Parkinson e os erros de diagnóstico, o que pode ser observado também na fala de outros participantes, L.C: "começou com problema na coluna, tanto que ele ia no ortopedista, fazia radiografia, depois começou com uma depressão muito profunda... A gente notava muito lento e ai ele foi acompanhado por um psiquiatra, o psiquiatra indicou para ele fazer uns testes psicológicos e ele fez... A sugestão do diagnóstico foi que ele estava com a demência de corpos Lewy... Aos poucos, outros sintomas foram aparecendo e então, foi diagnosticado com a Doença de Parkinson".

A forma como o diagnóstico foi dado e as sensações de receber essa notícia, variaram desde surpresa à negação e aceitação, I: "Eu recebi naturalmente, conforme recebo qualquer diagnóstico... Porque eu parto do princípio que essa doença dá nos seres viventes", M: “cê leva um baque... Eu tinha 56 anos, não tava na flor da idade, mas tava enxuto, tava bem na fita como se diz, ai vem aquele choque, saber que a doença ela é degenerativa, num tem cura" ainda, G: "Eu no... no começo eu não, eu não acreditava, eu inclusive acho que eu entrei até em de... em... em de... de... de... depressão". Ademais, um certo incômodo com a falta de informação acerca da doença por parte dos médicos foi manifestado, N: “Me deu remédio, eu tomei Prolopa... só que ai os médicos não explicavam direitinho o diagnóstico, só aumentava remédio, dava outro... Vários tipo de remédio passaram para mim, só remédio forte, ai vai daqui, vai lá, operei”. 
No que refere aos sintomas da doença, alguns participantes salientaram uma rápida evolução desses, como G: "Não, eu não sentia nada não... Eu fiquei de...dez anos sem...sem...se....se... sem sintoma nenhum... Depois que... apa... que ve... veio com carga total" e também, N: "Foi evoluindo, foi aumentando... ai eu fui diminuindo também. Hoje eu num faço mais nada das atividades que eu fazia". Além disso, foi observada pelos participantes uma maior dependência de suas cuidadoras e um comprometimento do próprio organismo, $\mathrm{C}$ : "Eu procuro me manter em atividade e independente. Independente eu não consigo mais... Tem algumas coisas que eu sou completamente dependente, eu só saio com a L. agora, porque eu tô caindo muito e se eu cair numa rua?!”, ainda, G: "Limitam, porque eu evito... evito sair, sair de... de casa... Evito sair, eu evito viajar. Mais em casa" e C: "Eu não viajo mais... Eu não tenho mais condições para viajar atualmente mais não".

Há uma incompatibilidade entre o tempo da doença e a evolução dos sintomas, alguns participantes apresentam maior comprometimento do que outros, independentemente do período da doença, como I: "Olha... nenhum... Num sinto nada. Tenho os meus movimento normais", N: "Tem um pouquinho de cada coisa... O pior é o tremor, a voz também é meia fraca”, G: "A fala! O equilibrio, o... o tre... o tre...tremor eu ainda... ainda relevo ainda, porque... porque eu ainda consigo fazer pa... parar. Num tá tão forte assim, é, mas o equilíbrio e a fala, tá... tá horrível poxa!" Ainda, foi destacado que o lado psicológico também sofre prejuízo, M: "Mas, que afeta a sua cabeça, uns mais outros menos, com certeza".

Verificou-se que mesmo havendo uma interferência dos sintomas no dia a dia dos portadores da DP, isso não os impede de executar suas atividades, M: "Num posso dizer que num interfere, interfere um pouco, que às vezes vocêfica um pouco mais desanimado, entendeu? Cê sente uma dorzinha que te incomoda... desmotiva... agora, impede não. Eu não deixei de fazer as coisas que eu fazia, em menor velocidade, em menor quantidade, mas faço, faço tudo sozinho". Alguns participantes relataram se retrair mais, por se sentirem constrangidos com o aparecimento dos sintomas, G: "A fala interfere, às vezes eu fico com... com ve... ve... vergonha de... de abrir um... um diálogo com as pessoas, fico constrangido... Eu fico... eu fico no meu... no meu canto... Fico... fico incomodado".

O uso da medicação não é suficiente para eliminar os sintomas, uma vez que não abrange todos os efeitos da doença, C: “Os medicamentos encobrem né... mas, tem alguns que não encobre, o freezing por exemplo, como as quedas, como o engasgo, como a 
deglutição (pausa) Ah, isso que cê tá vendo é brancos de memória. De vez em quando me dá um branco de memória, ai some tudo que eu ia falar, mas volta em quinze segundos a quarenta e cinco segundos".

Com relação ao auxílio oferecido pelo governo, alguns participantes relataram se sentir desamparados, N: "os remédios que não tem no governo, cê tem que comprar por sua conta... O governo só fornece alguns remédios... só Prolopa mesmo... alguns outros remediozinhos dá o desconto, mas os remédios muito caro o governo cai fora".

\section{Enfrentando a Doença de Parkinson: superando os obstáculos}

Foi relatada uma aceitação da doença por parte de alguns portadores da DP, N: “Eu aceito ela. Parkinson ele é coisa leve, eu num posso deixar a doença me levar... Me viro sozinho. Não me entrego pra doença. Então eu aceito a doença como uma coisa natural" e G: "com o tempo eu tive que aceitar né. Na...não... não houve jeito, essa é a realidade. Hoje eu aceito, porque a... a cada dia ela... ela avança mais.". Outros relataram que além de terem aceitado a doença, desenvolveram métodos de conviver de maneira mais leve com esta, como C: "Olha, eu quando comecei a construir uma fase de aceitação, eu cheguei à conclusão que eu precisava aprender tudo sobre a doença e comecei a estudá-la a fundo e resolvi inclusive escrever um livro".

Em decorrência da doença, modificações nas atividades diárias e na convivência com as outras pessoas surgiram, para alguns participantes de forma mais brusca e intensa do que para outros, que consideram viver sem alterações. Fora isso, alguns participantes relataram ter sentido um distanciamento das pessoas depois do aparecimento da doença, I: “Continuo, normalmente, fazendo tudo que eu fazia, em condições normais, conforme eu falei, eu vivo sem alteração, num tenho problema nenhum não, num tenha nada que diga que alterou isso ou aquilo... como se eu nem tivesse", N: "Afastaram muito meus amigos, mas eu num implico com isso não. Encaro isso como uma normalidade", C: "eu tenho o dia todo planejado, muito em função do remédio que eu tomo... Não dirijo há muito tempo também, eu cheguei à conclusão que nossos reflexos estão ruins, então eu não vou dirigir né, pra fazer mal a mim ou aos outros” e G: “eu... eu já... já fiquei limitado. Num podia fazer determinada coisa porquê vi... vinha um sin... um sintoma. Hoje, hoje eu não... não saio de casa sem...sem ter uma...uma outra pe... pessoa comigo... Sempre é a minha... a minha esposa comigo".

O suporte social oferecido pela família foi mencionado como positivo e motivador para os portadores de DP, o que os auxilia a lidar com a doença, M: “Aceitei bem, tenho 
muito apoio, minha família toda... Eu tenho duas filhas, a minha esposa, são bem cuidadosas" ainda, M: "O problema é as pessoas receber pro lado psicológico né, não é nem o lado físico... problema maior é a cabeça... Minha família sentiu mais do que eu e eu administro, no fundo eu acho que mexeu alguma coisa", também G: "Eu diria até que é excelente... Ela... ela faz... faz... tudo que eu... que eu... que eu esteja precisando. Ajuda muito mesmo. Inclusive eu... eu devo muito a ela, poxa!".

A convivência na Associação Parkinson Brasília é percebida pelos portadores de DP como muito positiva e prazerosa, além de fornecer um suporte, proporciona uma maior interação social, M: "Muitíssimo importante! Troca de informação... você se situar dentro da sua doença, você ajudar uma pessoa, você ser ajudado por alguma pessoa. Você conviver e cê viver, porque num é 'procê' ficar isolado na sua casa e não conviver... Vergonha de Parkinson eu não tenho não", ainda, N: "Eu acho bom porque tem jeito de se ajudar... Todo mundo ajuda, é a familia" e I: "Olha, é a minha segunda casa".

\section{Convivendo com a Doença de Parkinson: o olhar de quem cuida}

Percepções como maior isolamento social e dependência foram ressaltadas pelos cuidadores familiares, além de mudanças nos hábitos e atividades cotidianas, S.C: “ $A$ parte social justamente, que é mais complicada, porque ele quer ficar em casa... Outra coisa que me incomoda também, é que ele fala muito pouco e pelo problema da voz, isso tá afastando muito ele das pessoas, porque ele vai falar e não é só a gagueira, ele tem problema na formulação do pensamento e na hora de expressar verbalmente, então não sai o que ele quer falar e com isso ele não fica perto das pessoas, ele se afasta, não quer ir em nenhum evento, não quer ter que se comunicar", P.C: “Ela não visita ninguém, ela não vai pra lugar nenhum, porque acha que chega alguém e fica observando ela... Quando a pessoa começa a olhar pra ela, ela já fica imaginando coisas, que que aquela pessoa tá pensando em relação ao problema dela, ai ela evita sair" e A.C: "Ele dança, ele faz tudo, ele faz pilates... Num tem dificuldade nenhuma, dói, ele disse que quando são pesados os exercícios, que ele sente dor, mas ele é persistente sabe, ele faz!’. Outros evidenciaram ter ocorrido alterações cognitivas e um rebaixamento do humor dos portadores de DP, L.C: “É horrivel... e ter consciência, isso ainda é o que dói mais, ter consciência que a vida da gente tá se acabando ali e ele sem poder fazer nada... ai ele não vai ter depressão? Claro que vai ter depressão... Semana passada, fui no psiquiatra com ele e ele também falou que a depressão tá mais acentuada, talvez seja um momento de mais consciência, até perguntei pro médico, "Ele tem consciência da doença dele?", 
ele falou assim “tem”... Agora ele tem momentos em que ele não é lúcido, por exemplo, às vezes ele olha pra mim e diz assim 'Cadê a L.C?'”.

Divergências na comunicação entre cuidador familiar e portador da DP foi referida por parte dos participantes, S.C: “Até às vezes na teoria, é, parece tranquilo de falar, mas no dia a dia, as coisas ficam dificeis. Porque a gente quer ajudar, mas quer ajudar do jeito da gente e ele querem ser ajudados do jeito deles". Alterações na rotina que demandam adaptação por parte dos cuidadores familiares também foram enfatizadas, B.C: "A única coisa que alterou era que a gente sempre dava uns passeios assim, final de ano e ultimamente, nunca mais a gente passeou... Lugar nenhum, ele num gosta de sair de casa" e A.C: "A gente mudou um pouco esse ritmo de sair, de muita programação... Tudo tem que ser num ritmo mais lento, é tudo programado".

Foi consenso entre grande parte dos cuidadores a percepção de isolamento por parte dos portadores de DP, os quais por vezes, se retraem até dentro da própria casa, S.C: “As pessoas vão, se aproximam, ele se retrai e ai ninguém pode fazer nada. No mais, as pessoas continuam indo e ai acabam conversando comigo... A gente não vai a lugar nenhum, a gente não vai na casa de ninguém, nem dos filhos, que moram aqui”, ainda, S.C: "Sim! Até de mim e eu não sei como que eu venço isso... tô buscando e o que tá ajudando é isso, você vendo a experiência dos outros cuidadores que passam pelo mesmo problema, não tô sozinha nisso e depois, vou tentar aquela estratégia que a outra tá usando e que tá dando certo... Ele não admite também, um outro cuidador". Alguns cuidadores familiares relataram não perceber mudanças significativas, A.C: "Até aqui, pra mim num tá sendo assim, nada de anormal, de empecilho... Eu convivo bem, eu pensei que fosse mais dificil... Ele leva tudo assim, na brincadeira, eu acho que o emocional ai dele, ajuda muito. É, como cê enxerga e como cê lida com aquilo".

No que concerne ao diagnóstico da doença, uma rápida evolução dos sintomas foi observada por parte dos cuidadores familiares, L.C: "Quando foi diagnosticado, realmente foi assim, uma coisa brusca, ele, do momento para o outro, ele ficou totalmente dependente. Tanto que eu comprei cadeira de rodas assim, de um dia para o outro, aquela cadeira pro banheiro, cama de hospital, tudo foi providenciado e arrumado, as pressas". Alguns cuidadores familiares alegaram ter recorrido a terapias alternativas para ampliar as possibilidades de tratamento, A.C: “É tratamento espiritual, eu sei que pra pessoas que não conhecem, ficam assim... mas o M. é o exemplo vivo, se não fosse isso ele já 
estaria como os outros... fazendo cirurgia pra implantar coisa, cadeira de rodas, porque onze anos, né?".

\section{Experiência do cuidador familiar com a Doença de Parkinson: um desafio}

No que se refere a escolha do cuidador, foi relatado por parte dos cuidadores familiares ter sido algo automático, S.C: "Na realidade eu... a única, porque nós somos casados e ele teve o diagnóstico de Parkinson, então foi assim, meio automático... os filhos colaboram, mas são os três já são adultos, então, ficamos só nós dois e automaticamente é um pelo outro". Outros já sentiram a necessidade de dividir esse cuidado com alguém, recorrendo a cuidadores profissionais, L.C: "No início da doença do meu marido, eu tinha um cuidador durante o dia e ficava com ele à noite, normalmente à noite é mais tranquila porque ele acaba dormindo, mas, nem sempre era assim, às vezes eu acordava de madrugada com a cama toda molhada, ai eu tinha que dar banho nele, mudar a cama, virar o colchão, depois dele tá arrumadinho e aí eu ia tomar banho... Durante o dia eu sempre tive cuidador, depois como ele ficou muito confuso, a doença começou a intensificar, ai eu arrumei uma pessoa para ficar ele durante a noite".

A insegurança e o medo do futuro estiveram presente nos relatos, assim como uma comoção ao descobrir a doença, A.C: "Foi um choque né, que a gente nunca tá esperando por isso e quando eu soube foi no dia do meu aniversário de 60 anos, então, ele chorou o tempo inteiro e ai eu me despenquei também, porque a gente tem planos assim, a longo prazo né e a gente gosta muito de viajar, de sair e ficava assustado, com medo que aquilo ia ser um fator de limitação né, de impedir a gente de muita coisa... Foi um choque pra família né, porque ele muito novo, cê vê, ele tinha 55 anos".

Em relação ao significado de cuidar, parte dos participantes trouxe o amor, a disponibilidade e o fazer para outro aquilo que ele não consegue, como uma representação de cuidado, como P.C: "Cuidar é amor, quem ama cuida né?! Cuidar pra mim é você se dedicar, é você fazer as coisas no momento que ela tá precisando", S.C: "Cuidar é... eu até digo que eu me sinto como um bombeiro que está de prontidão para surgindo qualquer necessidade auxiliar, então eu fico de prontidão, é assim a minha visão de cuidar, é fazer pra ele o que ele não consegue fazer sozinho e ao mesmo tempo, não avançar de modo que isso acabe reduzindo as possibilidades dele, o que eu converso muito com ele é, o que você dá conta de fazer, faça... Ajudar, se eu puder, ou para pedir socorro para que ele seja ajudado".

No que se refere ao papel desempenhando pelo cuidador familiar e as sensações 
de exercer essa função, alguns participantes demonstraram uma grande frustração, por se tratar de uma realidade completamente inesperada e que não condiz com as expectativas de futuro que haviam sido traçadas, manifestaram também certo medo de estar no lugar do outro, dependente e necessitando de cuidados, S.C: "Num vou dizer que é ótimo, maravilhoso, eu ficar só cuidando dele, não é isso que quando a gente casa, a gente tá sonhando no final, o que que gente sonha, a gente sair, viajar... Ninguém se prepara pra ficar cuidando de uma familiar doente... Então vai e ai buscando adaptação... se eu fiz a opção para ficar cuidando dele e é esse papel que eu procuro interiorizar e aperfeiçoar nele... Eu estou no papel de cuidar dele, poderia ser ao contrario, poderia eu estar precisando dos cuidados dele, então, eu procuro desempenhar o meu papel com habilidade, com eficiência, com prazer e sobretudo com amor", L.C: “Ai, é difícil. É difícil (choro) tem dias que dá vontade de fugir... Porque a gente trabalhou a vida toda e agora que seria a oportunidade de viajar, de sair, ele não pode... É uma aceitação, mas dói, dói bastante (choro)".

O papel de cuidar é visto por alguns como uma obrigação, L.C: "Eu acho que num tem que fazer! Aquela obrigação né, num pode ficar de braços cruzados, tem que fazer mesmo... como é que eu me sinto? Me sinto horrível, mas fazer o que? Eu preferia não fazer né, porque ali eu estaria viajando, teria a vida que qualquer pessoa quer ter na idade que eu estou, mas, não me revolto, fico triste, porque realmente não é o que eu queria pra minha vida... Assumi esse papel, não tem como não assumir, não tem como não fazer né e tô vivendo, na medida do possível, tentando o máximo possível ser eu, né, eu L.C sem ser cuidadora". Outros cuidadores familiares se mostram mais conformados em exercer esse papel, não enxergando o exercício do cuidado como algo dispendioso, ainda que necessitem fazer algumas adaptações, B.C: "Eu acho assim, doença chega pra qualquer um né?! Então a gente tem que aceitar e cuidar né. Eu faço a minha parte... Um faz companhia pro outro e pronto" e A.C: "Eu tive que fazer uma adaptação né... Que aí já não era ele que ia cuidar de mim, que seria eu, futuramente, que vou cuidar dele, então eu trabalhei esse lado aí da minha cabeça, eu mesma... Quando precisar né, a gente vê se dá conta ou se não dá".

Em se tratando das implicações diretas que o papel de cuidador pode acarretar a vida daquele que o exerce, foi observada uma preocupação constante por parte dos cuidadores familiares e que muitos, passam a viver em função de quem necessita do cuidado, se inviabilizando, S.C: "Inclusive a aposentadoria, eu gostava muito de 
trabalhar, então foi uma precipitação, porque se ele não precisasse de mim, eu estaria trabalhando e essa inatividade, isso dai, me deixa, às vezes, com um grande ponto de interrogação, o que que eu estou fazendo? Eu não tô fazendo mais nada, eu estou ociosa, não estou fazendo as coisas que eu gosto, isso dai teve um impacto bem grande, eu tive assim uma queda bem grande na autoestima, porque eu sempre gostei muito de sair, fazer coisas e até aquelas coisas que eu gostava de fazer, agora eu num faço, não sei explicar porquê... Então agora, eu me coloquei nesse posto de bombeiro, sem fazer nada, só esperando apagar incêndio... Eu fico totalmente por conta dele, seguindo agenda médica, fisioterapia... única função”, L.C: “Exige uma dedicação quase que total né, eu tento não me anular perante essa doença, eu faço a minha vida, eu tenho encontros com as minhas amigas, eu vou no clube... mas interfere, por mais que a pessoa trabalhe esse lado que é nosso, acaba interferindo, porque eu por exemplo, se eu estou no clube eu não estou 100\% lá, eu fico “pô, será que tá tudo bem lá em casa?”, por mais que a pessoa procure ficar afastado do problema, eu pelo menos não consigo, sempre interfere".

Preocupações futuras devido às informações adquiridas sobre a doença também foram ressaltadas, B.C: "Eu num tenho nada assim pra reclamar não... possa ser que a tendência das coisas é piorar né?!", P.C: "Eu tô acompanhando ela já faz pouco tempo, porque antes, ela fazia as coisas dela sozinha... Ultimamente, num tá tão boa né, porque essa doença a pessoa num, não fica bom, parece que é regressiva, parece que invés dela melhorar, faz é piorar". Já outros, alegam não notar mudanças significativas em decorrência da doença, P.C: "Não, nunca me afetou em nada. Num me prejudicou em nada não, sou feliz do mesmo jeito, a gente cuida bem um do outro... É normal, tá, pra mim ela não tem essa doença".

Além de mudanças na estrutura da família, foi observada uma tendência dos filhos não serem tão presentes nos cuidados, S.C: “E os filhos, eu acho que tem aquela coisa de mãe que ainda eu é que devo ajudá-los, né? E poupá-los, eu procuro poupá- los o máximo, enquanto eu der conta sozinha e eu não quero que eles deixem os compromissos deles, porque eu já deixei, já deixei o meu trabalho, a função que eu tinha" e L.C: "Sim, mas mexe muito... mexe na estrutura da família".

Em se tratando da Associação Parkinson Brasília, os cuidadores familiares ressaltaram o fornecimento de suporte, a solidariedade e a troca de informação, assim como uma sensação de pertencimento e acolhimento, S.C: “A associação foi muito bom para nós e esse convívio com outras pessoas que tem o mesmo problema, com os 
cuidadores também, que enfrentam as mesmas dificuldades e ai a gente vai se armando de força, de coragem”, P.C: “Eu gosto, eu danço, cê vê que eu acompanho ali... Ela gosta, ela gosta de dançar, ela adora vir 'praqui', por isso que eu trago. Ó pensa num lugar que ela faz questão de vir, é aqui! Porque aqui, num só tem ela, ela tem uma multidão, são várias pessoas que tá com o mesmo problema que ela tem", ainda, A.C: "Eu acho interessante o trabalho da associação, acho que dá muito apoio, M. gosta muito de ir, se sente muito bem... É uma troca de experiências, cê conversa com um, você conversa com outro, ai há aquela troca de informação que eu acho muito importante".

\section{Discussão}

Os resultados corroboram com os principais dados apontados na literatura, que evidencia o papel da família como importante rede de apoio aos indivíduos que se encontram em condição de cronicidade. A família é fundamental no processo de aceitação e convivência com a Doença de Parkinson (Alvarez et al., 2016; Cetolin et al., 2012; Cobb, 1976; Navarro-Peternella \& Marcon, 2009).

Por ser considerada uma forte fonte de suporte social, a família é responsável pela produção e programação de cuidados e proteção, além de contribuir com a construção de vínculos relacionais e com a organização e adaptação às dificuldades e limitações acarretadas pela DP (Cetolin et al., 2012; Cobb, 1976; Kuster, Silva, Leite, \& Costa, 2014; Navarro-Peternella \& Marcon, 2009).

A literatura indica uma tendência dos portadores da DP à depressão e ao isolamento social. A depressão é um dos sintomas mais graves da DP e é desencadeada por uma carência de dopamina no organismo e, quando associada a outros fatores, tende a se intensificar. A depressão atinge cerca de $40 \%$ a $60 \%$ dos portadores da DP em alguma fase da doença (Barreto \& Fermoseli, 2017; Cetolin et al., 2012; Custodio et al., 2018; Faria, Lima, \& Pereira-Silva, 2019; Patto \& Freitas, 2012; Navarro-Peternella \& Marcon, 2009).

Estudos realizados mostraram que a depressão antecede os sintomas motores da Doença de Parkinson em 25\% dos pacientes. Ademais, verificou-se a presença de sintomas depressivos em $70 \%$ dos portadores da DP, que pode estar associado ao avanço da doença, uma vez que há uma tendência ao agravo no quadro dos sintomas, interferindo diretamente na qualidade de vida dos indivíduos (Custodio et al., 2018; Faria et al., 2019; Navarro-Peternella \& Marcon, 2009). 
A tendência ao isolamento social, também muito referida na bibliografia e citada nas entrevistas, está relacionada ao maior comprometimento físico, o qual pode estar ou não, acompanhando de perdas cognitivas. A família é avaliada como importante aliada, podendo auxiliar no combate a depressão e ao isolamento social, participando das atividades diárias e estimulando o convívio social (Cetolin et al., 2012; Kuster et al., 2014; Navarro-Peternella \& Marcon, 2012; Faria et al., 2019).

Para mais, cabe destacar que a Doença de Parkinson afeta não só o seu portador, mas a família como um todo, a qual está envolvida diretamente com todas as emoções e alterações vivenciadas. Dessa forma, é salientada na literatura a relevância do trabalho dos profissionais em conjunto com a família, a qual faz parte de todo o processo e também necessita de suporte e instrução para o manejo diário com os portadores da DP (Cetolin et al., 2012; Kuster et al., 2014; Navarro-Peternella \& Marcon, 2009).

Os grupos de apoio são de grande relevância, uma vez que se constituem em uma poderosa rede de apoio aos portadores da DP e suas famílias, proporcionando espaços de troca de saberes e experiências, mobilizando esforços na busca do bem-estar, da autonomia e da autoestima de seus integrantes (Alvarez et al., 2016; Kuster et al., 2014; Navarro-Peternella \& Marcon, 2009; Patto \& Freitas, 2012).

É evidenciado na literatura, assim como observado nas entrevistas realizadas, que os grupos de conivência, além de proporcionarem a troca de informação, favorecem a união e a socialização. São espaços de ajuda mútua que implementam ações voltadas para a melhora da qualidade de vida de seus membros (Alvarez et al., 2016; Kuster et al., 2014; Navarro-Peternella \& Marcon, 2009; Patto \& Freitas, 2012).

Em se tratando do diagnóstico da DP, foi verificada uma dificuldade em fechar tal diagnóstico, uma vez que não há um exame específico para concluir a investigação, a qual ocorre muitas vezes por exclusão, o que pode acarretar em erros de diagnóstico, como foi observado em quase todos os relatos dos entrevistados (Barreto \& Fermoseli, 2017; Cetolin et al., 2012).

Embora não haja uma relação direta entre o tempo da DP e o nível de dependência de seus portadores, a Doença de Parkinson por seu caráter degenerativo, tende a evoluir, o que implica no aumento progressivo dos sintomas, que por sua vez geram limitações, as quais interferem, direta ou indiretamente, nas atividades diárias dos portadores da DP e como já salientado e observado nas falas dos participantes, essas limitações podem contribuir para o isolamento social, comprometendo a qualidade de vida dos portadores 
da DP (Cetolin et al., 2012; Faria et al., 2019; Navarro-Peternella \& Marcon, 2009/2012).

Quanto às entrevistas realizadas com os indivíduos com a Doença de Parkinson, todos os entrevistados foram do sexo masculino, o que chama a atenção para outra informação apontada na literatura, a maior incidência da Doença de Parkinson em homens (Barreto \& Fermoseli, 2017; Cetolin et al., 2012; Navarro-Peternella \& Marcon, 2012; Faria et al., 2019). Além disso, em se tratando da pesquisa realizada, foi observado que dos 40 membros ativos e participantes das reuniões semanais na Associação Parkinson Brasília, 30 eram homens e 10 eram mulheres.

Constata-se, nas questões de saúde pública, uma atenção mais direcionada às demandas de cunho curativo e de reabilitação, ainda carece de uma atenção à saúde do doente de Parkinson, o qual se vê desassistido frente as políticas públicas, contando apenas com uma Portaria e um Projeto de Lei. O relato dos participantes mostra uma assistência que necessita ser revista, pois não atinge as demandas desse público, inclusive as básicas, como o fornecimento das medicações necessárias (Cetolin et al., 2012; Navarro-Peternella \& Marcon, 2009).

A Psicologia, no acompanhamento do portador da DP e sua família, trabalha mediante a compreensão da totalidade dos indivíduos envolvidos, visa colaborar com a promoção de saúde, na busca da aceitação da doença e do convívio com as alterações e limitações geradas, oferecendo suporte psicológico e auxiliando no enfrentamento de questões emocionais e relacionais que emergem ao longo desse convívio.

Cabe enfatizar a relevância do trabalho multidisciplinar, de forma a contemplar portadores da DP em todas as suas dimensões, compreendendo que a vivência da doença é um processo individual, dinâmico e permeado por significados, para mais, é crucial que os profissionais de saúde incluam a família nesse processo, entendendo a dinâmica familiar e valorizando papel que é exercido por esta, visando amenizar os impactos da doença (Barreto \& Fermoseli, 2017; Navarro-Peternella \& Marcon, 2009/2012).

\section{Considerações finais}

Com fundamento nos dados obtidos, constatou-se que o suporte social é um fator de proteção e um motivador para o enfrentamento da Doença de Parkinson, o qual dispõe 
de efeitos mediadores sobre a preservação da saúde dos portadores da DP, refletindo diretamente na qualidade de vida desses indivíduos.

A análise dos dados elucidados na pesquisa nos instiga a pensar que, abordar a Doença de Parkinson, implica trazer à tona um assunto de grande importância para a sociedade e que tem sido pouco divulgado à população, em especial no campo da saúde pública. Portanto, para além do suporte social familiar e de grupos de apoio, como é o caso da Associação Parkinson Brasília, é necessário que os portadores da Doença de Parkinson contem com ações políticas, econômicas e sociais que assegurem os seus direitos, de forma que estes tenham garantia de auxílio para enfrentar as alterações provocadas pela doença. Uma vez que o presente estudo não se dispôs a esgotar o tema, sugere-se o desenvolvimento de pesquisas que investiguem com maior precisão os efeitos das políticas públicas direcionadas aos portadores da DP.

\section{Referências}

Alvarez, A. M., Gonçalves, L. I. T., Schier, J., Hammerschmidt, K. S. de A., Souza, B. C., \& Valcarenghi, R. V. (2016). Grupo de apoio às pessoas com Doença de Parkinson e seus familiares. Extensio: Revista Eletrônica de Extensão, 13(22), 92101. https://doi.org/10.5007/1807-0221.2016v13n22p92

Barreto, M. A. M., \& Fermoseli, A. F. de O. (2017). A importância do acompanhamento psicológico sobre os indivíduos portadores da Doença de Parkinson e Parkinsonismo usuários de L-Dopa. Ciências Humanas e Sociais, 4(2), 29-38. Recuperado de https://periodicos.set.edu.br/index.php/fitshumanas/article/view/4120/2579

Brasil, Portaria $n^{\circ} 228$, de 10 de Maio de 2010. Aprova o Protocolo Clínico e Diretrizes Terapêuticas - Doença de Parkinson. Brasília, DF: Ministério da Saúde, Secretária de Atenção à Saúde. Recuperado de http://bvsms.saude.gov.br/bvs/saudelegis/sas/2010/prt0228_10_05_2010.html

Cabreira, V. \& Massano, J. (2019). Doença de Parkinson: Revisão Clínica e Atualização. Acta Med Port, 32(10), 661-670. https://doi.org/10.20344/amp.11978

Cetolin, S. F., Trzcinski, C., Mahl, A. C., Steffani, J. A., Luccas, T. N., \& Presta, A. A. (2012). Alterações Sociofamiliares na vida de pessoas com Mal de Parkinson usuárias da Saúde Pública. Unoesc \& Ciência, 3(2), 203-212. Recuperado de https://portalperiodicos.unoesc.edu.br/achs/article/view/2102/0 
Cobb, S. (1976). Social support as a moderator of life stress. Psychosomatic Medicine, $38(5), 300-314$.

Custodio, N., Alva-Diaz, C., Morán-Mariños, C., Mejía-Rojas, K., Lira, D., Montesinos, R., Herrera-Pérez, E., Castro-Suárez, S., \& Bardales, Y. (2018). Factors associated with depression in patients with Parkinson's disease A multicenter study in Lima, Peru. Dementia \& Neuropsychologia, 12(3), 292-298. https://doi.org/10.1590/1980$57642018 \mathrm{dn} 12-030010$

Dorsey, E. R., Constantinescu, R., Thompson, J. P., Biglan, K. M., Holloway, R. G., Kieburtz, K. et al. (2007). Projected number of people with Parkinson disease in the most populous nations, 2005 through 2030. Neurology, 68(5), 384-6.

Faria, L. J. F., Lima, P. M. R. \& Pereira-Silva, N. L. (2019). Resiliência familiar diante do diagnóstico da doença de Parkinson na velhice. Pesquisas e Práticas Psicossociais, 14(1), 1-18. Recuperado de http://pepsic.bvsalud.org/scielo.php?script=sci_arttext\&pid=S1809$89082019000100014 \& \operatorname{lng}=$ pt\&tlng=pt.

Ferreira, D. P. C. (2016). Percepções do cuidador familiar do idoso com doença de Parkinson em relação ao processo de cuidar (Tese de Pós-Graduação, Centro de Ciências da Saúde, Recife). Recuperado de https://repositorio.ufpe.br/handle/123456789/17529

Kuster, B. J. K., Silva, L. A. A., Leite, M. T., \& Costa, M. C. (2014). Cuidados de Enfermagem aos usuários com Doença de Parkinson na Atenção Básica de Saúde. Revista de Enfermagem da UFSM, 4(1), 10-18. http://dx.doi.org/10.5902/217976929074

Madureira, A. F. A., \& Branco, A. U. (2007). Identidades sexuais não-hegemônicas: processos identitários e estratégias para lidar com o preconceito. Psicologia: Teoria e Pesquisa, 23(1), 81-90. Recuperado de http://www.scielo.br/pdf/ptp/v23n1/a10v23n1.pdf

Minayo, M. C. S., Deslandes, S. F., Neto, O. C., \& Gomes, R. (2002). Pesquisa Social: teoria, método e criatividade. Petrópolis: Vozes.

Navarro-Peternella, F. M., \& Marcon, S. S. (2009). Descobrindo a Doença de Parkinson: impacto para o parkinsoniano e seu familiar. Revista Brasileira de Enfermagem, 62(1), 25-31. Recuperado de http://www.scielo.br/pdf/reben/v62n1/04.pdf 
Navarro-Peternella, F. M., \& Marcon, S. S. (2012). Qualidade de vida de indivíduos com Parkinson e sua relação com tempo de evolução e gravidade da doença. Revista Latino-Americana de Enfermagem, 20(2), 384-391. Recuperado de http://www.scielo.br/pdf/rlae/v20n2/pt_23.pdf

Patto, C. A. P., \& Freitas, T. (2012). Rompendo as Amarras da Doença de Parkinson. Brasília: Liber Livro.

Pinheiro, J. E. S. (2011). Doença de Parkinson e outros transtornos do movimento. Em E. V. de. Freitas; L. Py et al. Tratado de Geriatria e Gerontologia (pp. 285-291). Rio de Janeiro: Guanabara Koogan.

Ramos, F. P., Enumo, S. R. F. \& Paula, K. M. P. (2015). Teoria Motivacional do Coping: uma proposta desenvolvimentista de análise do enfrentamento do estresse. Estudos de Psicologia, 32(2), 269-279. https://doi.org/10.1590/0103166X2015000200011

Sant'Ana, L. A. J. \& D’Elboux, M. J. (2019). Suporte social e expectativa de cuidado de idosos: associação com variáveis socioeconômicas, saúde e funcionalidade. Saúde em Debate, 43(121), 503-519. https://doi.org/10.1590/0103-1104201912117

Silva, J. A. M. G., Dibai Filho, A. V., \& Faganello, F. R. (2011). Mensuração da qualidade de vida de indivíduos com a doença de Parkinson por meio do questionário PDQ-39. Fisioterapia em Movimento, 24(1), 141-

146. Recuperado de http://www.scielo.br/pdf/fm/v24n1/v24n1a16.pdf

Simonetti, J. P., \& Ferreira, J. C. (2008). Estratégias de coping desenvolvidas por cuidadores de idosos portadores de doença crônica. Revista da Escola de Enfermagem da USP, 42(1), 19-25. Recuperado de http://www.scielo.br/pdf/reeusp/v42n1/03.pdf

Straub, R. O. (2014). Health Psychology: A Biopsychosocial Approach. Michigan, EUA: Worth Publishers.

Valcarenghi, R. V. (2015). Vivendo com a doença Parkinson. (Tese de Doutorado). Universidade Federal de Santa Catarina, Centro de Ciências da Saúde, Programa de Pós-Graduação em Enfermagem, Florianópolis. Recuperado de https://repositorio.ufsc.br/handle/123456789/135671

Recebido em: 04/03/2020 
Aprovado em: 09/07/2020 